THE ANNALS OF "DUNAREA DE JOS” UNIVERSITY OF GALATI

FASCICLE XV ISSN - 1454 - 9832 - Vol. 2/2019

Article DOI: https://doi.org/10.35219/efms.2019.2.07

\title{
THE IMPACT OF STRENGTHENING EXERCISES ON THE FUNCTIONING OF QUADRICEPS MUSCLE IN TEENAGERS CHILDREN INVOLVED SPORT ACTIVITY AND NOT INVOLVED IN SPORT ACTIVITY
}

\author{
Lina LEVICKIENE ${ }^{1}$, Monika POCIENE ${ }^{2}$ \\ ${ }^{1}$ Klaipeda State University of Applied Sciences, Faculty of Health Sciences, Department of Physiotherapy and Beauty \\ Therapy, 1.levickiene@kvk.lt
}

\begin{abstract}
Research shows that the involvement of majority of Lithuanian schoolchildren in sports activities is insufficient. Lack of physical activity has an adverse effect on their growth and maturity. Scientists, who have studied the issue of physical activity of children in Lithuania, envisage obviously declining trends of physical activity. Research data show that physical activity of more than 50\% of boys and over 60\% of girls in Lithuania are not sufficient (Skurvydas, 2017). Physical activity is defined as any bodily movement produced by skeletal muscles that's requires energy expenditure.

The objective of the research: to assess the impact of strengthening exercises on the functioning of quadriceps muscle for teenagers children who are involved in sports activity or not involved in sports activity.

Conclusions: 1. After application of strength exercises the increase in thigh volume, quadriceps muscle thickness and strength were statistically significant $(p<0.05)$ in both groups: sporting and non-sporting. Quadriceps muscle thickness and muscle strength were statistically significantly greater $(p<0.05)$ in sporting group, and thigh volume increase was statistically insignificant greater $(p>0.05)$ in non-sporting group. 2. Difference in thigh volume, quadriceps muscle thickness and strength between the dominant and non-dominant leg was statistically insignificant $(p>0.05)$ prior to and after the application of strength exercises. 3. The closest correlation was between the quadriceps muscle thickness and thigh volume as well as between the quadriceps muscle strength and thickness. The relation between the quadriceps muscle strength and thigh volume was average or weak.
\end{abstract}

Keywords:Quadriceps muscle function, strengthening exercises, muscle strength, muscle thickness.

\section{Introduction}

In most children and adolescents, daily physical activity is inadequate as it does not meet the World Health Organization's recommendations on health-enhancing physical activity (at least 1 hour of moderate intensity daily physical activity) (Regional office for Europe of the WHO, 2017). According to these recommendations, it was found that in many countries of the world, including Lithuania, about one third and less students are physically active (Zumeras, 2014).

Lack of physical activity can affect many systems of the body: the condition of cardiovascular and respiratory systems is weakened, skeletal muscle capacity decreases, bone density and firmness deteriorates, physiological indicators of metabolism, the possibility of obesity or overweight is increasing.

General strength training is recommended during adolescence period, because optimal strength and muscle balance are critical for the quality growing skeleton. Muscle strength exercises improved muscle performance, increased motor performance, improved body composition and increased bone strength (Brody, Hall, 2018).
There is a linear relationship between overall physical activity and muscle capacity and flexibility (Maciuleviciene, 2015).

\section{Problem Statement}

The ever-decreasing physical activity among adolescents promotes various disorders of the body (obesity, cardiovascular changes, dysentery disorders, psychosocial ailments, skeletal muscle function limitations).

There are not many scientific articles analysing the differences in muscle structure and function between teenagers who involved sport activity and not involved in sport activity and, so it was important to find out how the difference in muscle strength, volume and thickness between these different participant group.

It was also important for us to find out how the muscle strengthening exercises program applied will affect the muscle structure and functions parameters of both groups. 


\section{THE ANNALS OF “DUNAREA DE JOS” UNIVERSITY OF GALATI \\ FASCICLE XV ISSN - 1454 - 9832 - Vol. 2/2019}

\section{Research Questions/Aims of the research}

Before the study of this research, the hypothesis was raised that strengthening exercises program would have a positive effect on the increase of quadriceps thigh muscle strength, thigh volume and thickness.

Task: 1 . To evaluate the change of the quadriceps thigh muscle strength, thigh volume and thickness of the teenage children who were involved sport activity and those who were not involved in sport activity. 2. To evaluate the strength, thigh volume and thickness of quadriceps thigh muscle of the dominant and nondominant leg. 3. To evaluate the correlation between the strength, thigh volume and thickness of quadriceps thigh muscle.

\section{Research Methods}

The study was conducted at the primary school, with the written consent of the school head and the parents of the children to participate in the study. In total, 18 boys were divided into 2 groups of 9 participants: sporting group was made up of boys who attended football classes after lessons, a non-sporting group made up ofboys who did not engage in active physical activity after lessons. The average age of the sporting group is $12.6 \pm 0.5$ years, while non-athletes are $12.4 \pm 0.5$ years old.

2 tests were conducted in both groups: before and after the study. The study organization scheme is shown in Figure 1.

\section{First Testing:}

- Determining the dominant leg

- Evaluation of muscle strength of the quadriceps thigh muscle

- Upper thigh measurement

- Determination of the thickness of the quadriceps thigh muscle

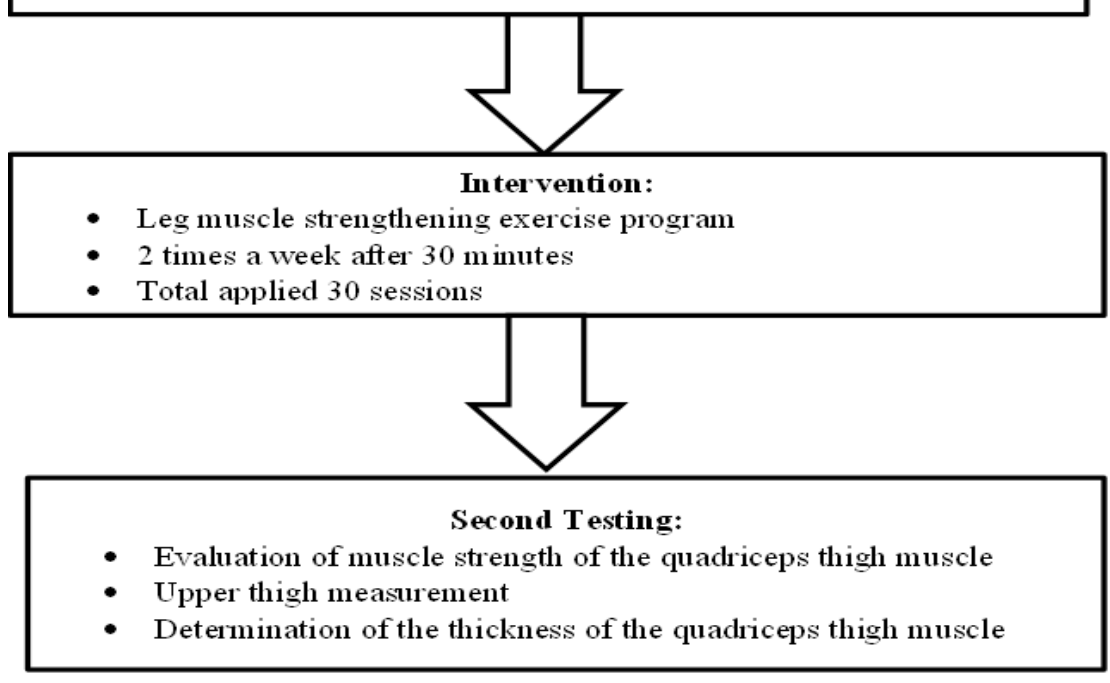

Figure 1. Study organization scheme

The following test methods were used in the study:

1.Ascertainment of dominant leg. The dominant leg was ascertained by the help of a ball. Participants were asked to come up to the ball and kick it. The dominant leg was determined by 3 trials.

2.Measurement of muscle force. The quadriceps thigh muscle force was measured by a manual Lafayette dynamometer. The resulting force was expressed in kilograms. During testing the static muscle strength, the position of manual dynamometer and the tested person was selected according to the requirements submitted by Reese (2012):

- The position of the tested person: sitting on the edge of the table, the thigh up to the harness lies on the table, the joint of the knee is bending at the angle of $45^{\circ}$.

- The position of dynamometer: the front surface of the calf $10 \mathrm{~cm}$ higher from the middle line of the ankle.

- The command to the tested person: to keep the leg in testing position and not allow for the tested person to move it (Reese, 2012).
During the study were performed 3 tests, from which the average was calculated. When the largest magnitude of muscle strength is gained, a signal sounds after which the measurement is completed. There were 30 seconds breaks between the tests.

3.Measurement of thigh volume. The volume of both thighs was measured the distance of $20 \mathrm{~cm}$ above the patella was chosen. The measurement was performed with a centimeter strip.

Measurement of muscle thickness. The thickness of the quadriceps thigh muscle was measured by ultrasound apparatus TITAN and using ultrasonic HST/10-5 MHz $25 \mathrm{~mm}$ linear sensors. The tests were performed in a lying position, relaxed. The quadriceps thigh muscle thickness was measured at 5 points between the upper edge of the patella and the anterior superior iliac spine, every $5 \mathrm{~cm}$ that is $5,10,15,20,25 \mathrm{~cm}$ in height from the edge of the patella. 


\section{Findings}

1.Quadricep thigh muscle strenght. Comparing the results of quadriceps thigh muscle strength in both groups (sporting and non-sporting) statistically significantly $(\mathrm{p}<0.05)$ increased both in the right and left leg. Before and after testing the quadriceps thigh muscle strength was statistically significantly $(p<0.05)$ larger in both legs of sporting group comparing to non-sporting group. Both group studyresult are show in Figure 2.

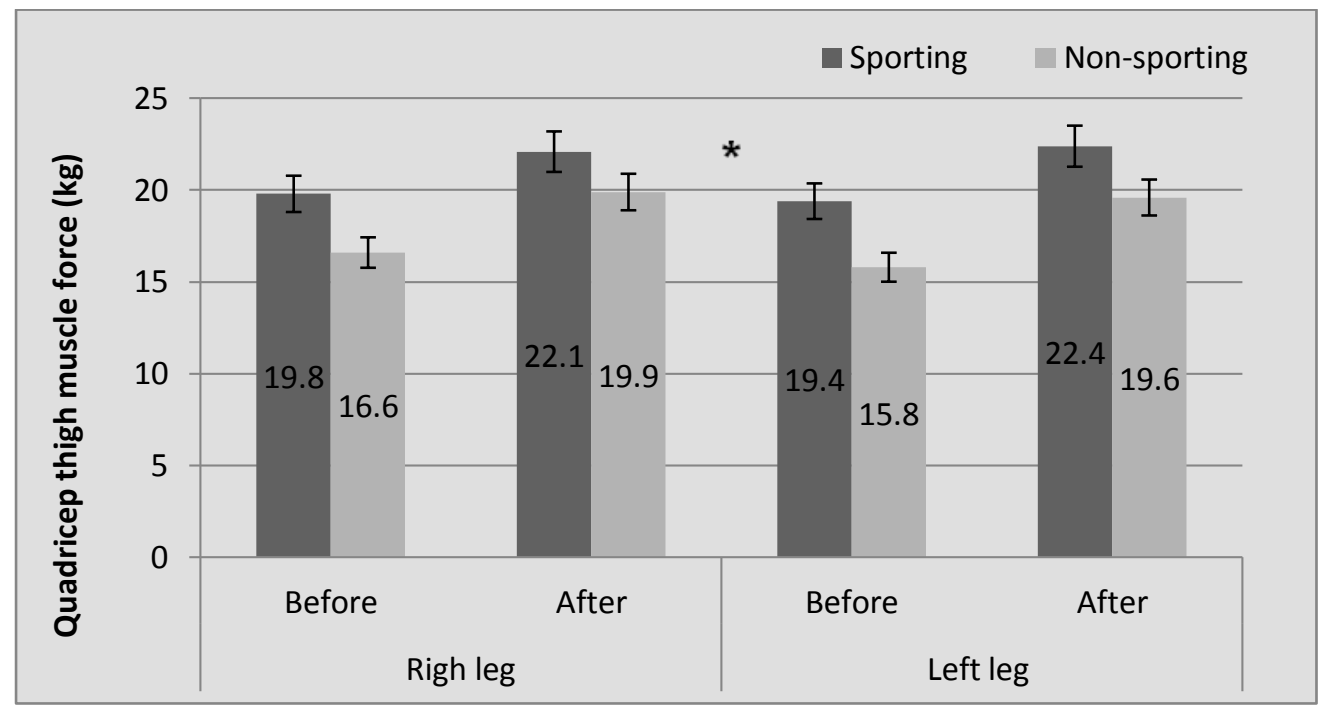

Figure 2. Distribution of quadriceps thigh muscle strength results among the participants $(*-p<0.05)$

After muscle strengthening exercises program was applied, the larger changes of muscle strength was noticed in non-sporting group (muscle strength change in the right leg $-3.3 \pm 2.4 \mathrm{~kg}$, in the left leg $-3.8 \pm 2.8 \mathrm{~kg}$ ) compared to a sporting group (muscle strength change in the right leg $2.3 \pm 1.9 \mathrm{~kg}$, in the left leg $-3.0 \pm 2.1 \mathrm{~kg}$ ).
2.Thigh volume. Comparing the results of thigh volume between both groups before and after the test, the higher volume in both legs was in the non-sporting group, however, there was no significant difference $(\mathrm{p}>0.05)$. Both group study result are shown in Figure 3.

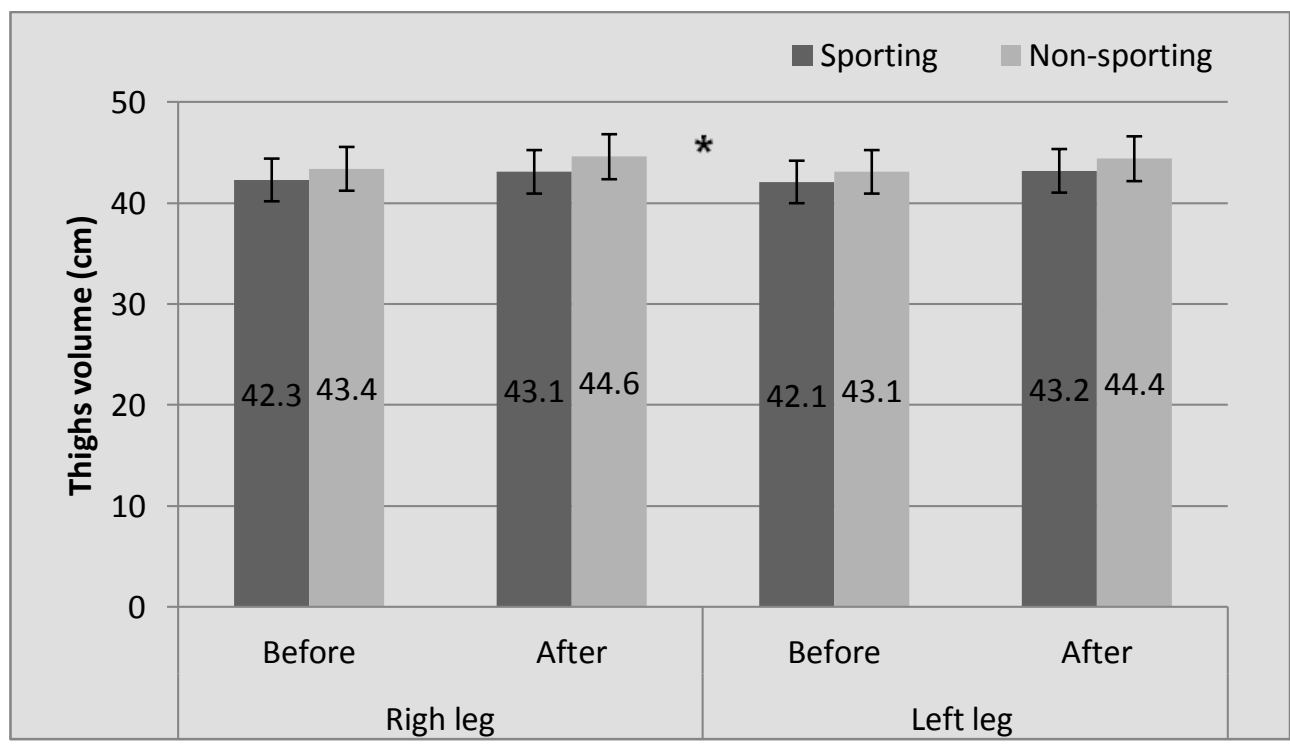

Figure 3. The averages of thighs volume of the right and left leg in both groups before and after test $(*-\mathbf{p}<0.05)$

Volume increase both in the right leg (sporting $0.8 \pm 1.0 \mathrm{~cm}$, non-sporting group $-1.2 \pm 0.8 \mathrm{~cm}$ ) and in the left leg (sporting group $-1.1 \pm 0.9 \mathrm{~cm}$, non-sporting group $-1.3 \pm 0.6 \mathrm{~cm})$.
3. Quadriceps thigh muscle thickness. The results of quadriceps thigh muscle thickness in the right (Figure 4) and in the left leg (Figure 5) of both groups 
statistically significantly increased $(\mathrm{p}<0.05)$, but not in all measured points. Comparing the results between the groups before testing, the larger muscle thickness was measured in both legs of the sporting group, however, the statistically significant difference $(p<0.05)$ was not obtained among all measurement points, but after strengthening exercise program the larger thickness was in non-sporting group in some measurement point.

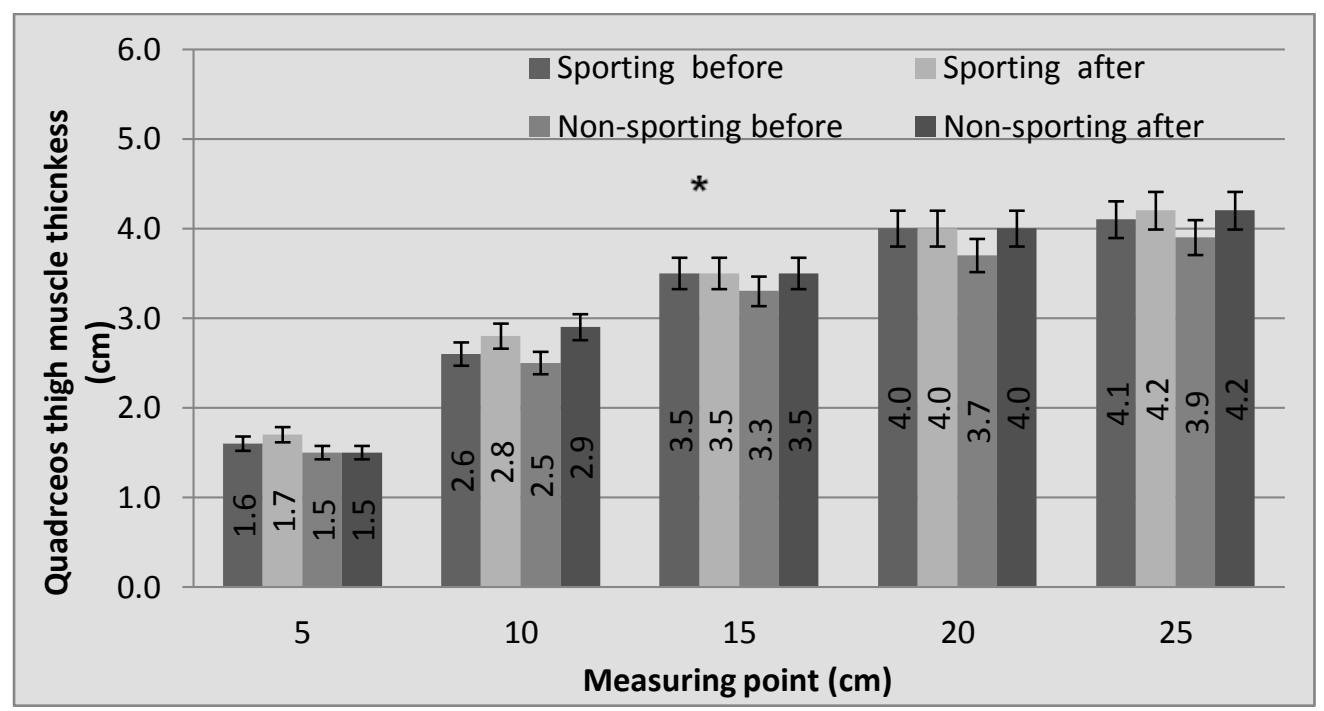

Figure 4. The results of quadriceps thigh muscle thickness of the right leg in the sporting and non-sporting before and after testing $(*-\mathbf{p}<0.05)$

After applied muscle strengthening exercises program in right leg the larger changes of thickness was noticed in sporting group at 10 measuring point $(0.2 \pm 0.1$ $\mathrm{cm})$, in non-sporting group at 10 point $(0.4 \pm 0.3 \mathrm{~cm})$, at 20 and 25 points $(0.3 \pm 0.2 \mathrm{~cm})$.

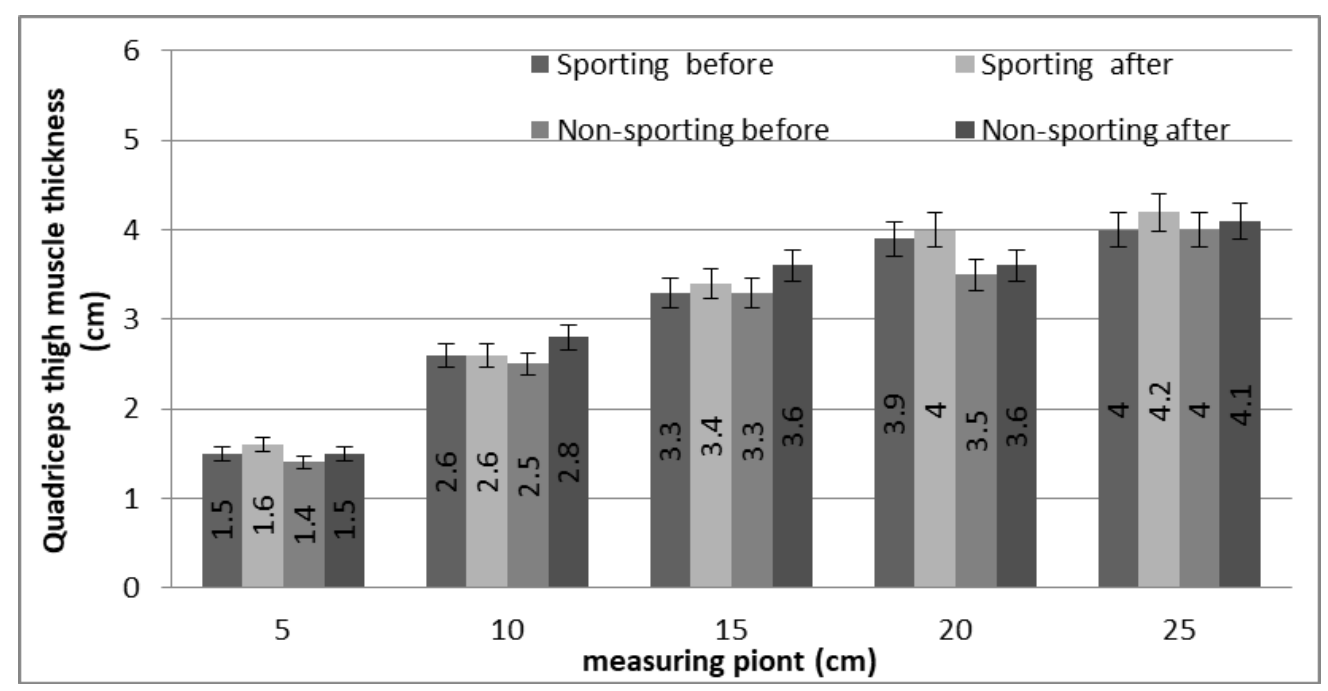

Figure 5.The results of quadriceps thigh muscle thickness of the left leg in the sporting and non-sporting before and after testing $(*-p<0.05)$

After muscle strengthening exercises program was applied in left leg, the larger changes of thickness was noticed in sporting group at 25 measuring point $(0.2 \pm 0.2$ $\mathrm{cm})$, in non-sporting group at 10 and 15 points $(0.3 \pm 0.2$ $\mathrm{cm})$.

4. Dominant leg. The ball-kick test showed that the all participants of the both group the dominant leg were right. The research data of the dominant and non- dominant leg showed that the results of all measurements in both groups statistically were not significantly different $(\mathrm{p}>0.05)$.

5. Correlation. Analyzing the correlation link between measured parameters, the stronger link was noticed in sporting group. In this group, statistically significant data $(\mathrm{p}<0.01)$ were obtained, and the strongest link was received between quadriceps thigh muscle 
thickness and thigh volume. Less link was determined between quadriceps thigh muscle thickness and muscle strength The average strength link was received between muscle strength and thigh volume.

In non-sporting group the correlation links between the measured parameters were weaker than in sporting group, and most of the obtained data was statistically insignificant. In this group the positive correlation link was determined between thigh volume and quadriceps thigh muscle thickness. The link between quadriceps thigh muscle strength and thickness was positive as well. The weak link was received between thigh volume and quadriceps thigh muscle strength and statistically insignificant results $(\mathrm{p}>0.01)$ and $(\mathrm{p}>0.05)$.

\section{Discussions}

Our research showed that the tested parameters (quadriceps thigh muscle thickness, strength and thigh volume) statistically increased significantly $(\mathrm{p}<0.05)$ after application of strengthening exercises. This conformed to other research works. Referring to the research performed by foreign authors during 4 weeks, 5 times per week applying 2 different strengthening exercises programs, a statistically significant increase in quadriceps thigh muscle thickness and strength was received in both groups (Cho et al., 2018).

The performed research proved that muscle thickness, as well as muscle strength, increases by training. Since the muscle strength and muscle thickness were higher in the sporting group than in non -sporting group, it can be stated that the results of the study coincided with the data of references, suggesting that with increased muscle volume, the muscle develops more force (Friesenbichler et al., 2018; McArdle et al., 2014).

It became clear that better change in the results between measurements was received in non-sporting group than in sporting group. Actually, it occurs because the sporting children are more trained, therefore, due to applied exercises, the indexes of measured parameters were less different. The rate of adaptation depends on training, less training means the greater indexes of adaptation. The sporting persons need physical loads of larger extent and intensity (Skurvydas, 2017).

After the research, it turned out that the results of the measured parameters between the dominant and nondominant leg statistically were not significantly different ( $p>0.05$ ). The research performed by McCreesh and Egan (2011) showed that the thickness of front calf muscle group of the dominant leg was statistically significantly larger among football-players, but not among control group (non-sporting) persons (McCreesh, Egan, 2011). The results of the research performed by Legerlotz and colleagues (2010) were similar to our research data. The authors who studied the children's two-folded muscle architecture (muscle thickness, distribution corner of fiber and length of fibers) noticed that statistically there was significant difference between the left and right leg (Legerlotz et al., 2010).
It is known that isometric muscle strength depends on muscle thickness. Our results matched with the data of foreign authors that a strong correlation link exists between quadriceps isometric muscle strength and muscle thickness (Brody, Hall, 2018; McArdle et al., 2014).

\section{Conclusions}

After application of strengthening exercises program, the increase in thigh volume, quadriceps muscle thickness and strength was statistically significant $(\mathrm{p}<0.05)$ in both groups: sporting and non-sporting. Quadriceps muscle thickness and muscle strength was statistically significantly greater $(\mathrm{p}<0.05)$ of sporting group, and thigh volume increase was statistically insignificant greater $(\mathrm{p}>0.05)$ in non-sporting group.

Difference in thigh volume, quadriceps muscle thickness and strength between the dominant and nondominant leg was statistically insignificant $(p>0.05)$ prior to and after the application of strengthening exercises program.

The closest correlation was between the quadriceps muscle thickness and thigh volume as well as between the quadriceps muscle strength and thickness. The relation between the quadriceps muscle strength and thigh volume was average or weak.

\section{References}

1. Brody L. T., Hall C. M. Therapeutic exercise: moving toward function. $4^{\text {th }}$ edition. Philadelphia: Wolters Kluwer; 2018.

2. Cho J., Lee K., Kim M., Hahn J., Lee W. The effects of double oscillation exercise combined with elastic band exercise on scapular stabilizing muscle strength and thickness in healthy young individuals: a randomized controlled pilot trail. Journal of Sport Science \& Medicine. 2018 May 1; 17(1): 7-16.

3. Friesenbichler B., Item-Glatthorn J. F., Neunstöcklin F., Casartelli N. C., Guilhem G., Maffiuletti N. A. Differences in trunk and thigh muscle strength, endurance and thickness between elite sailors and non-sailors. Sport Biomechanics. 2018 Jun; 17(2): 216-226.

4. Legerlotz K., Smith H.K., Hing W.A. Variation and reliability of ultrasonographic quantification of the architecture of the medial gastrocnemius muscle in young children. Scandinavian Society of Clinical Physiology and Nuclear Medicine. 2010 May; 3 (30): 198-205.

5. Maciuleviciene E. Paauglių iš Lietuvos ir Vokietijos fizinio aktyvumo, požiūrio $\mathrm{i}$ ji ir priežasčių, trukdančių fizinei veiklai, dimensijos. Sporto mokslas.. 2015; 4(82): 30-36.

6. McArdle W.D., Katch F.J., Katch V.L. Exercise physiology: energy, nutrition, and human performance. $8^{\text {th }}$ edition. Philadelphia: Lippincott Williams and Wilkins; 2014.

7. McCreesh K., Egan S. Ultrasound measurement of the size of the anterior tibial muscle group: the effect of exercise and leg dominance. Sports Medicine, Arthroscopy, Rehabilitation, Therapy\&Technology. 2011 September 13: 3(1):18. Retrieved from 
8.https://www.ncbi.nlm.nih.gov/pmc/articles/PMC3180254 I

9. Reese N.B. Muscle and sensory testing. 3th edition. St. Louis, MO: Elsevier; 2012. Saunders Regional Office for Europe of the World Health Organization (2017). Towards more physical activity: Transforming public spaces to promote physical activity - a key contributor to achieving the Sustainable Development Goals in Europe. Denmark: Copenhagen. Retrieved from http://www.euro.who.int/_data/assets/pdf_file/0018/35304 3/2017_WHO_Report_FINAL_WEB.pdf?ua $=1$

10. Skurvydas A. Judesiųmokslas: raumenys, valdymas, mokymas, metodologija, reabilitavimas, sveikatinimas, treniravimas. 2th edition. Kaunas: Vitae Litera; 2017.

11. Zumeras, R. Mokyklinio amžiaus vaikų fizinio aktyumo skatinimas. Vilnius: Sveikatos mokymo ir ligu prevencijos centras; 2014. 